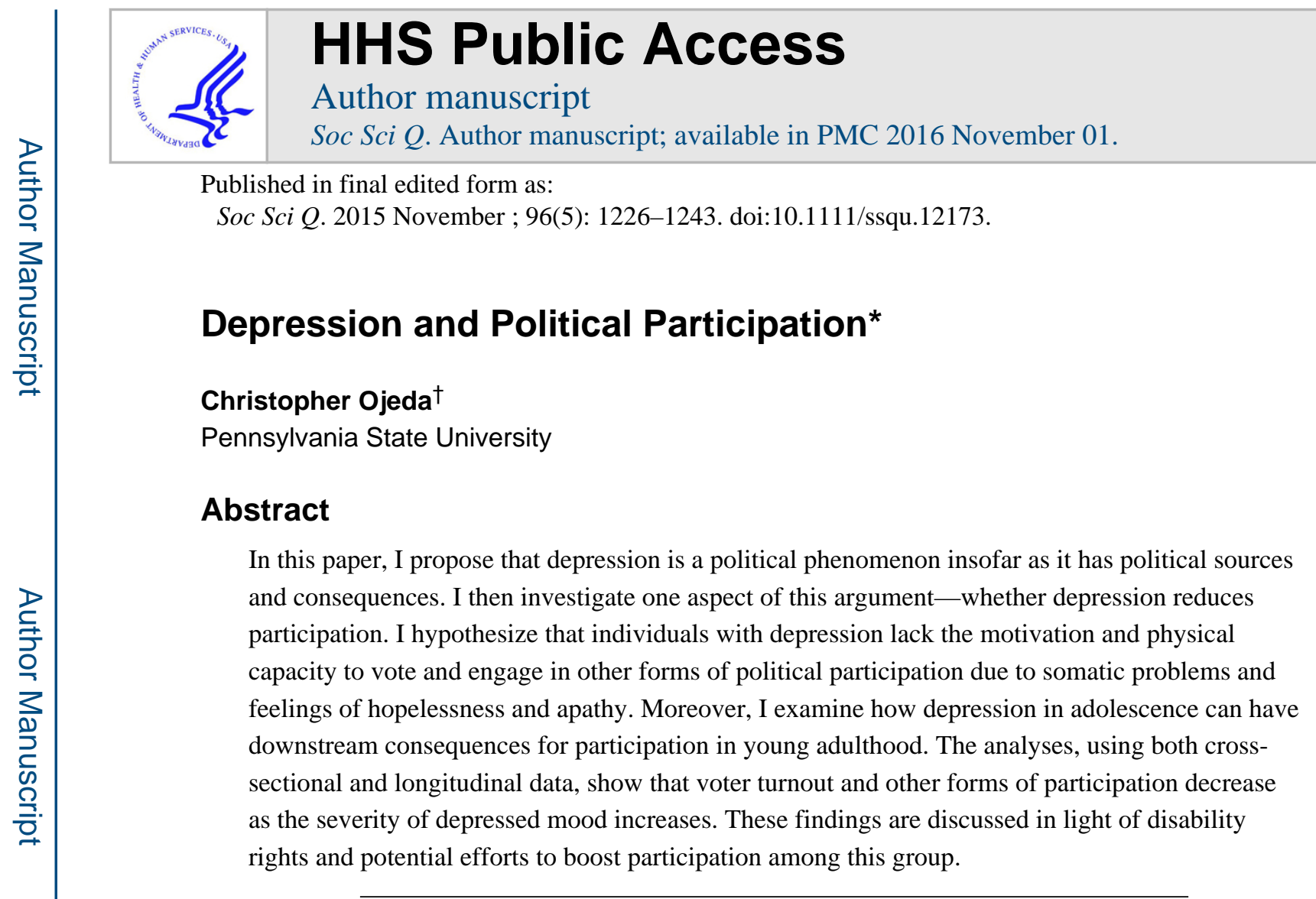

Depression has typically been defined in terms of its psychological components and, to a lesser degree, its social components. But might depression also be a political phenomenon? There are several reasons to believe this is so. First, the sources of depression might be political at least in part. The Surgeon General has reported that the primary problem of depression is the inadequate distribution of treatment rather than the lack of effective treatment (Goldman 2000). Problems of distribution are primarily political and economic. The second reason to believe that depression might be a political phenomenon is that it has political consequences. I demonstrate in this paper that the individuals with depression are less likely to participate in politics than are individuals without depression. The identification of a depression-participation gap adds to a growing body of research showing that individuals with poor health and physical and mental disabilities have an unequal say in the political process (Schur et al. 2002, Schur \& Adya 2013, Pacheco \& Fletcher 2014). It also raises questions about other political consequences of depression. Are individuals with depression less trusting, less efficacious, or less interested in politics? Do individuals with depression have distinct attitudes from those without depression?

That the sources and consequences of depression have political contours is further magnified by the fact that depression and its treatment are distributed in social and political wayswomen, racial minorities, and the poor are more likely to report symptoms of depression (Accortt, Freeman \& Allen 2008, González et al. 2010). In other words, individuals from politically underrepresented groups disproportionately suffer from depression at least in part

\footnotetext{
*I thank Eric Plutzer, Jenae Neiderhiser and members of her research lab, Emily LeDonne, Lee Hannah, Elizabeth Carlson, and members of the Center for American Political Responsiveness at Penn State for their helpful comments.

${ }^{\dagger}$ Corresponding Author: Ph.D. Candidate, The Pennsylvania State University, Department of Political Science, 314 Pond Laboratory, University Park, 16801 (ojeda.christopher@gmail.com).
} 
because of barriers to treatment which are partially rooted in politics. Depression then facilitates and reinforces existing political inequalities along gender, race, and class lines. Indeed, it is difficult to conclude that depression is not a pressing political problem when nearly one-fifth of Americans, often from disadvantaged backgrounds, report experiencing depression at some point in their life.

As a first step to better understanding depression as a political phenomenon, I ask: how does depression reduce political participation? Using data from the General Social Survey, I examine how depression disrupts the motivation and resources necessary for participation. Next I investigate possible developmental consequences by asking: how does depression in adolescence affect political participation in young adulthood? Research on adolescent depression reveals its negative ramifications on adult functioning. I use data from the National Longitudinal Study of Adolescent Health to show that these negative ramifications also include reduce political participation. I then consider four pathways through which adolescent depression might have an effect: personal efficacy, social interaction, educational attainment, and partisan attachment. I conclude by discussing depression in the context of disability, specifically comparing the medical and social models of disability and the implications of each for reducing political inequality.

\section{Depression in the United States}

The Diagnostic and Statistical Manual (DSM-IV), published by the American Psychiatric Association, defines major depressive disorder as "the loss of interest or pleasure in nearly all activities" (Association 2000). The common symptoms of depression include loss of energy, low self-esteem, concentration problems, changes in eating and sleeping patterns, and thoughts of suicide. Its mildest consequences might include reduced productivity at work or strained social relationships, while the most severe consequences might include a catatonic state, suicide attempts, or suicide. Indeed, the World Health Organization recently concluded that depression is the leading cause of disability among non-elderly adults in the United States (Mathers, Fat \& Boerma 2008).

One of the earliest systematic studies of depression prevalence in the United States, the National Comorbidity Survey (NCS), estimated lifetime prevalence (i.e., having experienced depression in the past) to be $17.1 \%$ and 12-month prevalence (i.e., having experienced depression in the past 12-months) to be $10.3 \%$ (Kessler et al. 1994). More recent findings from the National Comorbidity Survey Replication (NCS-R) were consistent with those from the NCS: lifetime prevalence was estimated at $16.2 \%$ and 12-month prevalence was estimated at $6.6 \%$ (Kessler et al. 2003). The NCS-R is critical to our understanding of depression as a political phenomenon because it connects the experience of depression to key characteristics of the population, including sociodemographics, comorbidity, role impairment, and treatment (Kessler et al. 2003). The study found a higher prevalence of depression among younger adults, women, individuals without a high school education, the unmarried, and the poor. Unfortunately, this same study found that only " $57.3 \%$ of respondents with 12-month [depression] received some type of treatment in the 12 months before the interview" (Kessler et al. 2003, p. 3102). Moreover, only 21.6\% of respondents received treatment that was deemed "adequate" by the team of psychiatrists, psychologists, 
and doctors conducting the study. This finding is consistent with earlier research that shows substantial under-treatment of depression in the United States (Hirschfeld et al. 1997, Olfson et al. 2002).

While depression is often discussed in clinical terms, sub-clinical depressive symptoms are also important as they affect a larger portion of the population. In the sections that follow, the term depression refers to symptoms that merit or would merit a clinical diagnosis, while the term depressed mood refers to the experience of one or more symptoms regardless of their clinical status. Thinking about depressive symptomology in terms of a gradient rather than a threshold allows for a more thorough investigation of how depressed mood-rather than a knife-edge, clinical diagnosis of depression - affects behaviors. Moreover, a depressed mood spectrum captures the effects of clinically significant but non-major depression, such as dysthymia and minor depression (Lavretsky \& Kumar 2002).

\section{Depression and Politics}

Models of political participation have not examined depression, or mental health more generally, as thoroughly as other factors like motivation, recruitment, or resources (Brady, Verba \& Schlozman 1995, Rosenstone \& Hansen 1993, Verba \& Nie 1972). Perhaps the research that most clearly addresses a mental health-participation linkage comes from Plutzer and Wiefek (2006) and Schur and colleagues (2003). Plutzer and Wiefek found that turnout was affected by personal efficacy, but unrelated to a "nervous-sad" scale, symptoms of mental illness, or feeling positive about life (2006). Schur and colleagues found that mental impairment was unrelated to internal efficacy, external efficacy, or civic skills (2003). While these studies indicate that mental health is unrelated to political behavior, they also come with some limitations that should be considered. The former, which examines voting in Chicago mayoral elections, uses a sample of African-American inner-city women and is therefore not nationally representative. The latter uses broad measures of mental disability - whether respondents have trouble learning, remembering, or concentratingwhich may be reflective of depression, but may also reflect any number of mental health problems. Therefore, to the best of our knowledge, the central question of this paper-what is the effect of depression on political participation?-has not been investigated with both well validated measures and on a nationally representative sample.

I propose two reasons why depression reduces the probability of political participation. The first reason is that depression reduces the motivation to participation. Individuals with depression tend to have a sad, anxious, or flat mood and often report feelings emptiness, hopelessness, and apathy (Ainsworth 2000, Melges \& Bowlby 1969). If a feeling of hopelessness, or the lack of a "perceived capability to derive pathways to desired goals" (Snyder 2002), extends to the political domain then depressed individuals will express a lower level of internal efficacy (e.g., "I'm incapable of making a difference") or a lower level of external efficacy (e.g., "government doesn't care what I think") or both. Political trust, which can be thought of as positive anticipation of government behavior (Dunn \& Schweitzer 2005), might also be affected by feelings of hopelessness, which is fundamentally a negative expectancy about the future. Individuals with depression interpret information through negative schemata (Beck 1963) and are therefore prone to be distrusting 
of government if the negative schemata extend to information about politics. Because efficacy and trust motivate participation (Abramson \& Aldrich 1982, Clarke \& Acock 1989, Pattie \& Johnston 1998), it seems likely that depression impacts participation via these pathways.

The second reason draws on the logic of the resource model of participation (Brady, Verba \& Schlozman 1995). I argue that political participation requires physical exertion in addition to the traditionally studied resources of money, time, and civic skills. The physical demands of participation has been extensively demonstrated by research that shows that physical disabilities substantially lower an individual's probability of voting (Schur et al. 2002). Depression likewise reduces the somatic capacity of an individual and therefore reduces the resources an individual has for political participation. Somatic complaints, including a lack of energy (Chakraborty et al. 2012), headaches, neck pain, and muscle soreness (Muñoz et al. 2005), and a heavy feeling in the arms and legs (Vaccarino et al. 2008), are common among those experiencing depression. More recent research by Pacheco and Fletcher (2014) further corroborates the physicality of political participation as they find a negative correlation between general health and political participation; this would presumably encompass any effect of depression or other mental health problems.

Finally, evidence of the burden created by depression is well documented in the economic domain and provides some insights for politics. Depression is shown to reduce productivity at work, both through absenteeism and what has been dubbed "presenteeism" (Stewart et al. 2003). Absenteeism occurs when an individual does not show up to work. Presenteeism occurs when an individual shows up to work but is less productive than they might otherwise be absent the depression. If an individual with depression fails to attend work on election day then why would we expect him or her to make it to the polls? If an individuals with depression is making errors at work on election day, might they also make errors on their ballot? Extending the logic from these studies suggests that the political domain might also suffer from absenteeism in the form of non-voting and presenteeism in the political domain in the form of "incorrect" voting.

\section{Adolescent Depression and Politics}

I also consider depression's developmental effects on political participation in addition to the consequences of contemporaneous depression that I articulated earlier. Research shows that impairment to adult psychosocial functioning, such as educational attainment, social ties, and healthy lifestyles, can result from adolescent depression independent of depressive symptoms experienced in adulthood (Glied \& Pine 2002, Puig-Antich et al. 1993). Might this also be true of political participation? There are several reasons why it might be. The foremost reason, at least with respect to voting, is that participation in a citizen's first eligible election impacts participation in subsequent elections (Plutzer 2002). Depression in adolescence may lead to non-voting in an individual's first election which then sets him of her on a trajectory to become a habitual non-voter later in life. That is to say that depression in adolescence may create an inertia that guides the probability of participation over the life course. 
Inertia aside, there are also mediating factors that link depression in adolescence to participation in adulthood. I explore four of these outcomes in this paper: social interaction, party identification, educational attainment, and personal efficacy.

\section{Social interactions}

Social interactions increase participation by leveraging feelings of social desirability regarding norms of participation (Gerber, Green \& Larimer 2008, McClurg 2003). Individuals with depression tend to be socially isolated (Rubin \& Coplan 2004), have reduced intimacy in their close relationships (Murphy 1985, Tse \& Bond 2004), and are more withdrawn and less talkative (Ainsworth 2000). If depression diminishes the influence of social desirability through less frequent social interaction, then a motivation for participation has been removed and the likelihood of being mobilized reduced.

\section{Party identification}

Strength of PID enhances participation by increasing motivation, reducing the need to gather information about candidates (Abramson \& Aldrich 1982), and increasing the likelihood of being mobilized (Huckfeldt \& Sprague 1992). But because individuals with depression often lack a sense of belongingness (Cockshaw \& Shochet 2010), we might expect partisan attachments to be weaker.

\section{Educational attainment}

Education increases turnout by developing the requisite civic skills; individuals with stronger verbal skills and more exposure to a social science curriculum tend to be the most political activity (Hillygus 2005). Adolescent depression has been shown to impair educational outcomes, including attainment and performance (Glied \& Pine 2002, Humensky et al. 2010, Lewinsohn et al. 2003), so we might expect education to account for some of the effect of adolescent depression on participation.

\section{Personal efficacy}

The feelings of hopelessness associated with depression could, in the political domain, translate to a low level of internal efficacy (e.g., "I'm incapable of making a difference") or a low level of external efficacy (e.g., "government doesn't care what I think") or both. Because efficacy motivates participation (Abramson \& Aldrich 1982, Clarke \& Acock 1989, Pattie \& Johnston 1998), it seems plausible that depression affects participation through reduced efficacy.

\section{Analysis}

Two datasets are employed in this analysis: The General Social Survey (GSS) and the National Longitudinal Study of Adolescent Health (Add Health). The General Social Survey is used to test the hypothesis that adult depression reduces adult voting. The Add Health is used to test the hypothesis that adolescent depression reduces voting and other forms of participation in young adulthood. One dilemma often encountered with mental health research is the overreliance on samples of the clinically ill and the under-sampling of those without mental health diagnoses. Fortunately both datasets overcome this problem. The GSS 
is a nationally representative sample of adults in the United States and provides variation across gender, race, income, education, and age. This ensures that the sample represents the full range of depressed moods experienced in the US population. Although restricted to young citizens, Add Health is also a nationally representative sample. The Add Health makes up for the shortcomings of the cross-sectional GSS data by allowing the temporal and cumulative effects of depression on political behavior to be disentangled.

\section{Analysis of GSS Sample}

The GSS is an annual (1972-1993) and biennial (1994-2010) survey that asks a range of questions regarding social, political, and economic issues. The 1998 GSS questionnaire included questions about both depressed mood and voting. Although the total sample size is 2,832 , the questions about depressed mood randomly appear on only three of the six versions of the questionnaire thereby reducing information about depressed mood to only a subset of respondents.

The dependent variable is self-reported turnout and was measured by asking respondents whether they had voted in the 1996 presidential election. About $68 \%$ reported voting. The key independent variable is a scale that was created by summing answers to four questions about depressed mood: "In the past 30 days, how often did you feel:

- so sad nothing could cheer you up?

- hopeless?

- that everything was an effort?

- $\quad$ worthless?"

Valid responses are none of the time, a little of the time, some of the time, most of the time, and all of the time, with each scored zero to four. The scale ranges from $0-16$, in which 0 represents an individual with no depressed mood and 16 represents an individual with the most severe depressed mood. The scale was reliable, $\alpha=0.81$. Because so few respondents report a severe depressed mood, the higher values are collapsed into a single value so that the scale ranges from 0 to 9 (alternate specifications are discussed in footnote 1). The scale is then transformed so that it ranges in value from 0 to 1 (mean $=0.30, \mathrm{SD}=0.29$ ).

An initial examination of the bivariate relationship between depressed mood and voting is shown in Figure 1. The graph plots a loess line predicting self-reported turnout across values of depressed mood. The probability of voting sharply decreases as the severity of decreased mood increases from 0 to 1 . Respondents who report no depressed mood have a 0.75 probability of voting, while respondents who report the most severe depressed mood have a probability of voting that is less than 0.5 .

The multivariate analyses are logistic regressions that predict self-reported turnout using depressed mood. I run several types of models to control for possible confounding factors, including a demographics model, a partisan strength model, a general health model, a social capital model, and a happiness model. The final model combines all these variables. All models use weights (wtssall) in order to adjust for the unequal probability of selection due to 
variation in the number of adults in sampled households. Dummy variables are created for sex $(1=$ female; mean $=0.51)$, race $($ black $=1$, mean $=0.13$; non-black $/$ non-white $=1$, mean $=0.07)$, and marital status $(1=$ married, mean $=0.57)$. Education is measured by the number of school years completed by the respondent and ranges from 0 to 20 (mean $=13.3, \mathrm{SD}=$ 2.9). Income is measured using estimated family income adjusted to 2000 constant dollars and rescaled to increments of $\$ 1,000$ (mean $=\$ 48,839, \mathrm{SD}=\$ 37,756$ ). Age ranges from 18 to 89 (mean $=44.5, \mathrm{SD}=15.8$ ). Partisan strength is a folded 7-point party identification scale that ranges from 0 , or no affiliation, to 3 , or strong party identification (mean $=1.70$, $\mathrm{SD}=0.96$ ). General health is measured using self-reported that includes poor, fair, good, and excellent. Dummy variables are created for good $($ mean $=0.47)$ and excellent $($ mean $=$ 0.32 ) with poor/fair serving as the reference category. Church attendance is measured a 9category ordinal variable ranging from 0 , or never, to 4 , or once a month, to 8 , or more than once a week (mean $=3.62, \mathrm{SD}=2.75)$. Finally, happiness is self-reported as very happy, pretty happy, or not too happy. Dummy variables are created for very happy $($ mean $=0.32)$ and pretty happy (0.56) with not too happy serving as the reference category; happiness is included to ensure that depression is not simply picking up a "happiness" effect (Flavin \& Keane 2012).

The results from the logistic regressions are presented in Table 1 and confirm the findings from the bivariate analysis. The results show that the probability of voting decreases as the severity of depressed mood increases, even after controlling for demographic characteristics, partisan strength, general health, church attendance, and happiness levels. Consistent with past research, more educated, richer, and older respondents were more likely to vote. Likewise is true of respondents who had a stronger partisan identification and attended church more regularly. Also shown in Table 1 are the first differences for the statistically significant variables in the full model. The first differences are estimates of the percentage change in the probability of voting given a standard deviation change in the continuous variables or a 0 to 1 change in the dichotomous variables, while all other variables are held at their median. The results show that a one standard deviation change in depressed mood has a comparable sized-effect to a one standard deviation change in income or a change in marital status from single to married. ${ }^{1}$

The findings provide evidence of a depression-turnout linkage in a nationally representative sample that is of a magnitude that warrants further consideration. This effect holds even after controlling for age and education, which are the primary predictors of turnout, key demographic characteristics such as race, gender, and class as well as a host of plausible confounding factors such as partisan strength, general health, church attendance, and happiness. One additional concern needs to be addressed: the temporal ordering of the depression and turnout variables. The measure of depressed mood is based on experiences in

\footnotetext{
${ }^{1}$ These findings are robust to other specifications of the depressed mood scale. A model in which the dependent variable is not topcoded produces a similar-sized effect. To further verify that the top-coding of respondents with severe depressed mood did not affect the results, a separate "severity" variable was created that measures the difference between a respondent's score and the top value of 9 for respondents with scores above 9 . Because this variable is not significant—either because there is a threshold on the degree to which increases in depressed mood affect voting behavior or because the sample size is very small for values of depressed mood greater than 9-it was omitted from the final model specification. Similar and statistically significant results are also produced by using a logged version of the depressed mood scale, which again suggests that the effect on voting decreases at higher values of depressed mood.
} 
the 30 days prior to the interview. The measure of turnout is based on an election that occurred about a year and half before the interview. Therefore turnout temporally precedes the experience of depressed mood for respondents in the data. This is a common problem in survey-based cross-sectional studies of political behavior - the measurement of turnout usually precedes the measurement of education, income, marital status, and party identification. While less than ideal, this mismatch will only downward bias estimates of the depressed mood effect. There is continuity in depressed mood across the life course such that many of the respondents who would have reported depressive symptoms at the time of the election will also report depressive symptoms at the time of the interview. The same is true of respondents who reported no or few symptoms. In contrast, a smaller number of respondents who experienced depressive symptoms at the time of the election will report no or few symptoms at the time of interview and vice versa. These latter respondents will muddy the depression-turnout linkage because they give the appearance that depression and turnout are unrelated. I therefore conclude that the depression-turnout gap is real and, in all likelihood, underestimated.

\section{Analysis of the Add Health Sample}

The National Longitudinal Study of Adolescent Health (Add Health) is a panel study that follows adolescents as they transition into adulthood. The first wave of data collection, which occurred in 1994-1995, consisted of a nationally representative sample of 7-12th graders (the sample includes private, religious, and public schools). The second wave of data collection occurred in 1995-1996 and the third wave of data collection occurred in 20012002 when respondents were between the ages of 18-28. The sample in Wave I has 20,745 respondents, the sample in Wave II has 14,738 respondents, and the sample in Wave III has 15,197 respondents. Measures of depressive symptoms are available in all three waves, and measures of political behavior are available in the third wave.

Add Health has several measures of political behavior, including self-reported vote and a participation scale. Self-reported turnout is measured by asking eligible respondents whether they voted in the 2000 election. About $41 \%$ of respondents reported voting. Political participation is a dichotomous measure based on whether respondents reported one of the following activities: participating in a political club or organization, contributing money to a political party, contacting an official, running for public office, running for non-public office, or attending a rally. About $7.8 \%$ report at least one of the activities.

Depression is measured using items from the Center for Epidemiologic Studies Depression Scale (CES-D) (Radloff 1977). The scale consists of 20 items, 19 of which are available in Wave I and Wave II and nine of which are available in Wave III. The nine common items are: "How often was each of the following things true during the past week?

- You were bothered by things that don't usually bother you.

- You felt that you could not shake off the blues.

- You felt that you were just as good as other people.

- You had trouble keeping your mind on what you were doing. 
- You felt depressed.

- You felt that you were too tired to do things.

- You enjoyed life.

- You felt sad.

- You felt that people disliked you."

Response options range from 0 to 3, and include never or rarely, sometimes, a lot of the time, or most of the time or all of the time. Items are coded so higher values represent more severe depressive mood. A depression score is created for each wave by summing these items. Although the summed scale only uses nine of the 20 CES-D items, it includes items from each of the four CES-D subscales, which are positive affect, negative affect, interpersonal relationships, and somatic complaints. Equivalent versions of an abridged CES-D scale have been used elsewhere (Meadows, Brown \& Elder Jr 2006). The summed scale ranges from 0 to 27 , where 0 indicates no depressed mood and 27 indicates the most severe depressed mood. The values from Wave I and II are highly correlated (0.58) and are combined to create an adolescent depressed mood scale. The scale is then transformed so it ranges from 0 to 1 (mean $=0.24, \mathrm{SD}=0.16, \alpha=0.86$ ). The Wave III values represent young adult depressed mood and are also transformed so they range in value from 0 to 1 (mean = $0.17, \mathrm{SD}=0.15, \mathrm{a}=0.80)$.

An initial examination of the relationship between depressed mood and political behavior is shown in Figure 2, which shows a loess line predicting self-reported turnout and other forms of participation using depressed mood. In each case, both adolescent and adult depressive mood are negatively related to political activity. The multivariate analyses are logistic regressions that predict self-reported turnout and political participation using both adolescent and adult depressed mood. ${ }^{2}$ All analyses use weights to adjust for the unequal probability of selection and panel attrition; all models control for standard demographic characteristics, including sex, race, education, age, general health, as well as characteristics of parents, including parental income, education and civic engagement. ${ }^{3}$

Dummy variables are created for sex $(1=$ female; mean $=0.49)$, and race $($ black $=1$, mean $=$ 0.14 ; non-black/non-white $=1$, mean $=0.10$ ). Education is measured by the number of school years completed by the respondent and ranges from 6 to $22($ mean $=13.0, \mathrm{SD}=1.9)$. Age at the time of the Wave III interview ranges from 18 to 28 (mean $=21.0, \mathrm{SD}=1.7$ ). Parental income is measured in increments of ten thousand dollars, ranging from $\$ 0$ to $\$ 100$ (mean $=4.6, \mathrm{SD}=4.6$ ). Parental education is measured by two dummy variables that indicate the highest degree earned (high school $=1$, mean $=0.42$; college or above $=1$, 0.43). Parental civic engagement is measured as a dummy variable based on self-reported

\footnotetext{
2Ideally, a model that draws on longitudinal data would control for unobserved time-invariant unit heterogeneity by using fixed effect or changes scores; however, this approach is not feasible with the current data because the dependent variables are measured in only Wave III.

${ }^{3} \mathrm{~A}$ basic demographic model is preferred to another in which more controls variables, such as partisan strength, religious attendance, or social capital, are included, because these variables represent potential mediators of the relationship between depressed mood and participation. The emphasis here is in identifying the total effect of depressed mood on participation and testing mediating factors later in the analysis.
} 
participation in any of the following organizations: parent/teacher organization, military veterans' organization, labor union, hobby or sports group, or civic or social organization (mean $=0.53$ ). A control variable for general health is also included. General health is measured by responses to the question "In general, how is your health?" Response options range from 1-5 and include excellent, very good, good, fair, and poor. Responses are reverse coded and then transformed to a $0-1$ scale $($ mean $=0.75, \mathrm{SD}=0.22)$.

The results from the logistic regression are presented in Table 2. Adolescent depressed mood negatively affects turnout and other forms of political participation. Adult depressed mood negatively affects turnout, but not other forms of political participation. Education, parental income, and parental education positively predict turnout and participation. Black respondents are more likely to be politically active, while females are less likely to be so. Age negatively predicts participation. ${ }^{4}$

Table 2 also displays the first differences in the predicted probability of voting and participating. First differences are calculated as the percentage change in the probability of voting given a half standard deviation shift in the continuous variables or a 0 to 1 shift for the dichotomous variables, while holding all other variables at their median. The results show that depression has similar-sized effects on voting as general health and parental income. With respect to participation, depression has similar-sized effects as age and parental civic engagement. Comparisons between the effects of depression and dichotomous variables are more difficult to assess. On the one hand, 0 to 1 changes in race and parental education exert larger effects on voting than does a one standard deviation change in depressed mood. On the other hand, a 0 to 1 change in depressed mood, while not reported in Table 2, has a larger effect than a 0 to 1 change in either race or parental education. The same is true of comparisons between depressed mood and gender and parental education in the participation model. Thus, while the GSS showed an association between the depressed mood and participation, the longitudinal data allows me to demonstrate a casual linkage between them.

\section{Mediation in the Add Health Sample}

Why does adolescent depressed mood affect voting and participating? While the mechanisms underpinning the contemporaneous effects of depression are straightforward, the answer to this question is less clear and merits further consideration. This is especially true in light of the fact that adolescent depression affects participation even when individuals show no recurring depressive symptoms in young adulthood. Earlier I suggested four potential mediators: social interactions with friends, affiliation with a political party, educational attainment, and personal efficacy. I hypothesized that adolescent depression

\footnotetext{
${ }^{4}$ Because adolescent depressed mood and young adult depressed mood are moderately correlated $(r=0.40)$, it is possible that adolescent depressed mood is simply an indicator of recurring or more severe young adult depression, in which case adolescent depression is not exerting an independent effect on voting or political participation. To test this possibility, I conduct analyses in which I restrict the observations to those in the bottom 25 th percentile of young adult depressive symptoms (i.e., those with the fewest depressive symptoms). The resulting sample maintains the range of values for adolescent depressed mood from the full sample, with the exception of the 10 observations in the top 0.07 percent of depressive symptoms. The multivariate analyses that use the restricted sample produce similar-sized and significant coefficients as do the analyses that use the full sample, suggesting that adolescent depressed mood is important independent of young adult depressed mood.
} 
negatively affects each of these factors and, in turn, negatively affects political participation. Mediation analyses will identify which of these factors, if any, provide a statistical accounting for the observed depression-participation linkage.

Social interaction with friends is measured by asking respondents "In the past seven days, how many times did you just 'hang out' with friends, or talk on the telephone for more than five minutes?" Response options range from 0 times to 7 or more times (mean $=4.33, \mathrm{SD}=$ 2.4). Partisan affiliation is measured dichotomously based on the question "Do you identify with a specific political party?" About $35 \%$ of respondents answered affirmatively. Educational attainment is measured as the highest grade completed by the respondent, with responses ranging from 6 to 22 (mean $=13.19, \mathrm{SD}=2.0$ ). Personal efficacy is measured using responses to the question "When you get what you want, it's usually because you worked hard for it." Response range from 1, or strongly disagree, to 5, or strongly agree (mean $=4.06, \mathrm{SD}=0.87) .{ }^{5}$ All the mediators are measured at Wave III, with the exception of personal efficacy which is measured at Wave II.

In order to estimate the proportion of the adolescent depression's total effect mediated by each of the four variables, I use regression-based analysis and then use a bootstrap method to obtain standard errors and assess the statistical significance of the mediated effects; this procedure is done using the mediation package in R (Tingley et al. forthcoming). Each mediator is analyzed in a separate model because little is known about the pathways from depressed mood to participation and we want to err on the side of identifying potential mediating factors rather than ruling them out. The analyses control for adult depressed mood, gender, race, age, education, general health, parental income, parental education, and parental civic engagement. ${ }^{6}$

The results from the mediation analysis are shown in Table 3. The two sections in the table correspond to 1) models that predict voting, and 2) models that predict the broader array of activities in the political participation scale. Within each section, the rows represent separate mediation analyses and are ordered from strongest mediating effect to weakest mediating effect. Because voting and participation are binary outcomes, the coefficients can be interpreted as changes in the probability of observing each outcome given a one unit change in depressed mood. The proportion of the total effect that is mediated can be calculated by comparing the indirect effect to the total effect. For example, model one is the effect of adolescent depressed mood on voting mediated through educational attainment. ${ }^{7}$ The total effect is the sum of the direct and indirect effects (e.g., $-.112+-.062=-.174$ ), which means that $36 \%$ (i.e., $[-.062 /-.174] \times 100$ ) of the total effect of adolescent depressed mood on voting is mediated through educational attainment. For both voting and political participation, the effect of adolescent depressed mood is partially mediated through

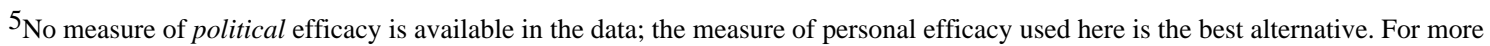
on the relationship between personal and political efficacy, see Fernandez-Ballesteros et al. (2002).

${ }^{6}$ The model for personal efficacy does not control for adult depressed mood in the first step, which predicts personal efficacy, because adult depressed mood is measured in Wave III while personal efficacy is measured in Wave II. The model for education does not include respondent education as a control variable because it is now being used as the mediating variable.

${ }^{7}$ The total effects vary by a small amount from row-to-row because of small differences in sample size.
} 
educational attainment and party identification, weakly mediated through social interaction, and not at all mediated through personal efficacy.

\section{Sensitivity Analysis}

Mediation analysis entails the sequential ignorability assumption that is not always met with observational data (Imai et al. 2010). This assumption can be expressed in two ways. First, the error terms from the model predicting the mediator do not correlate with the error terms from the model predicting political participation. Second, there are no omitted confounders that correlate with both depressed mood and each of the mediating variables. Violations of the sequential ignorability assumption might lead to incorrect inferences from the mediation analyses. Imai and colleagues (2010) have shown that sensitivity analyses are a useful tool for assessing how large a correlation, either between error terms or with an omitted confounder, would be required to undermine the inference of mediation. As explained in Appendix A, I test the degree to which the mediation analysis results are robust to these violations.

The results of the sensitivity analysis show that the mediating effects of education and party identification on voting are robust to a moderate violation of the sequential ignorability assumptions. For example, if an omitted confounder were correlated 0.20 or higher with education and with depressed mood then the mediating effect would in fact be zero. With respect to participation, the mediating effect of education and party identification are somewhat sensitive to the violation of the sequential ignorability assumptions and therefore merit further attention before they are confirmed or disproved as mediators. For example, an omitted confounder correlated 0.10 or higher with education and with depressed mood could account for the mediating effect of education. The effects of social interaction appear very sensitive in models of voting and participation and should be interpreted cautiously in this light.

\section{Discussion}

Depression is a much too common problem in the United States. Past research has identified economic, familial, and social consequences of depression, to which we can now add political consequences. Depression consistently and negatively affects voting and political participation. More than just contemporaneous effects, depression also has developmental consequences for political behavior. Adolescent depression has the potential to set individuals on a trajectory of political disengagement in adulthood. Results from the mediation analysis further indicate that the effect of adolescent depressed mood on political behavior operates by reducing educational attainment and partisan affiliation. Although it was not possible to examine with available data, political efficacy, interest, and knowledge might also be impaired by depression.

\section{Depression as a Mental Disability}

The evidence, both in this paper and elsewhere, shows that depression has a disabling effect across life domains and should be characterized as a mental disability. But are the sources of depression's disabling effects biological, social, or a combination of the two? How this 
question is answered - using either the medical model of disability or the social model of disability - has implications for policies that seek to address it and its consequences, including the depression-participation gap. The medical model would characterize depression as an illness whose consequences can only be primarily eliminated through its clinical diagnosis and treatment (Organization 2004). The social model would characterize depression as a result of systemic barriers to the well-being and functioning of individuals in society which can only be remedied through social accommodations (Oliver 1990). Because theorizing in the field of disability studies has tended to focus on physical disabilities and learning disorders, mood disorders such depression have been largely unattended.

To date, depression has been primarily understood as a psycho-medical condition and therefore studied through the medical model of disability, although not explicitly stated as such. Emphasis has been on the psychological origins and processes underpinning depression and how they might be treated through psychiatric and medical means. Thus the primary remedies for depression are therapeutic and pharmacological treatments. However helpful treatment may be, it is still not a panacea: it can only address depression after an individual has become depressed. It cannot prevent the onset of depression or change the social circumstances that give rise to and perpetuate the experience of depression.

It is therefore worthwhile to theorize about depression in terms of the social model, especially because the experience of a mood disorder such as depression is largely rooted in social circumstances. Depression is socially-situated in so far as it is not something that simply "happens" to someone but arises out of the circumstances of life. This is compounded by the fact that traditionally disadvantaged groups disproportionately experience depression. These facts mean that the consequences of depression can be traced to their sociopolitical origins. Still, it is not readily clear-which is not to say it is impossible - how depression might be socially accommodated like other disabilities are accommodated. The common example is that individuals in a wheelchair can and should be accommodated through the provision of wheelchair ramps in lieu of stairs which are the standard accommodation for abled-bodied persons. But what are reasonable accommodations with respect to voting for individuals with depression?

While the answer to this question is beyond the scope of this paper and should be left to future theorizing, it is worth anticipating a few possible response. The first and obvious solution is the universal prevention of depression; this represents the ideal outcome. However, short of that, there are a few other plausible responses based. One is to focus on the motivational consequences of depression. Earlier I argued that individuals with depression would be less likely to participate because they lacked the motivation to do so. The issue of motivation presents new challenges to the social model of disability which has tended to focus on mobility, vision, hearing, or cognition. Indeed, the concept of accommodation within the social model assumes the presence of a motivation that cannot be realized due to the structure of the environment. But are there parallel accommodations when it is motivation itself that is impaired? As a first cut it would seem that accommodating a lack of motivation to engage in extracurricular activity must entail social interaction; individuals with depression, left to their own devices, are unlikely to motivate themselves to go to the polling booth. 
The second possible response to the question of accommodations is to focus on the physical capacity of participation. I argued that individuals with depression would be less likely to participate because they lacked the somatic capacity to engage in the physical requirements of participation. The issue of physicality, however, seems secondary to the issue of motivation. Would making participation less physically-demanding increase participation among individuals who are have low motivation to begin with? The answer is a partial yesit should at least help among individuals who have some initial interest in politics. The physicality of participation has been addressed with respect to other disabilities: individuals who cannot see or walk have been accommodated in ways that have increased participation among these groups. Thus it may worthwhile to devise less physically-demanding forms of participation to accommodate at least some individuals with depression.

\section{A Political Cycle of Depression}

Future research into depression as a political phenomenon should take several avenues. One avenue, based on the prima facie evidence thus far, is the possibility of a political cycle of depression. This cycle would entail three steps: 1) individuals with depression are unlikely to participate in the political process, 2) the lack of participation leads to underrepresentation and a lack of policies that benefit those with depression, and 3) the lack of beneficial policy outcomes perpetuates the experience of depression. And so it repeats. This idea is illustrated in Figure 3.

The black arrow indicates that public policies addressing mental health have often lagged (e.g., housing policies, employment policies), although attempts to target issues of mental health have been made (e.g., The Mental Health Parity Act of 1996, The Affordable Care Act) with varying degrees of success (Klick \& Markowitz 2006). Thus policy has the potential to both perpetuate and mitigate the prevalence of mental health issues including depression. The gray arrow, as I empirically demonstrated in this paper, indicates that individuals with depression are much less likely to participate in politics because they lack the motivation and physical capacity to do so. Finally, the white arrow indicates the possibility that individuals with depression are underrepresented because of their lack of political voice at the ballot box. Research has demonstrated such a pattern among other underrepresented groups, such as the poor (Hill \& Leighley 1992), which raises the possibility that a pattern would also hold for individuals with depression. Although this cycle may have face validity, there has been little systematic empirical research to confirm any of the linkages and therefore uncertainty of its veracity remains.

Perhaps more important is to know how this cycle interlocks and reinforces other challenges to democracy, such as the income-participation gap, the underrepresentation of women and racial minorities, and the exclusion of individuals with disabilities. These groups disproportionately suffer from depression which further problematizes the possibility of a political cycle of depression. Political inequality is compounded if the conditions that lead to a reduced political voice (i.e., poverty, gender, race) also give rise to depression and all of its burdens. Future research should investigate whether depression is a mechanism that reduces the political voice of these groups and thereby reproduces the inequalities they face. 


\section{References}

Abramson, Paul R.; Aldrich, John H. The decline of electoral participation in America. The American Political Science Review. 1982:502-521.

Accortt, Eynav Elgavish; Freeman, Marlene P.; Allen, John JB. Women and major depressive disorder: clinical perspectives on causal pathways. Journal of Women's Health. 2008; 17(10):15831590.

Ainsworth, Patricia. Understanding depression. Univ. Press of Mississippi. 2000

Association. American Psychiatric. Diagnostic and statistical manual of mental disorders: DSM-IVTR®. 2000 American Psychiatric Pub.

Beck, Aaron T. Thinking and depression: I. Idiosyncratic content and cognitive distortions. Archives of General Psychiatry. 1963; 9(4):324. [PubMed: 14045261]

Brady, Henry E.; Verba, Sidney; Schlozman, Kay Lehman. Beyond SES: A resource model of political participation. American Political Science Review. 1995; 89(02):271-294.

Chakraborty, Kaustav; Avasthi, Ajit; Kumar, Suresh; Grover, Sandeep. Psychological and clinical correlates of functional somatic complaints in depression. International Journal of Social Psychiatry. 2012; 58(1):87-95. [PubMed: 21177704]

Clarke, Harold D.; Acock, Alan C. National elections and political attitudes: The case of political efficacy. British Journal of Political Science. 1989; 19(4):551-562.

Cockshaw, Wendell David; Shochet, Ian. The link between belongingness and depressive symptoms: An exploration in the workplace interpersonal context. Australian Psychologist. 2010; 45(4):283289.

Dunn, Jennifer R.; Schweitzer, Maurice E. Feeling and believing: the influence of emotion on trust. Journal of personality and social psychology. 2005; 88(5):736. [PubMed: 15898872]

Fernández-Ballesteros, Rocío; Díez-Nicolás, Juan; Caprara, Gian Vittorio; Barbaranelli, Claudio; Bandura, Albert. Determinants and structural relation of personal efficacy to collective efficacy. Applied Psychology. 2002; 51(1):107-125.

Flavin, Patrick; Keane, Michael J. Life satisfaction and political participation: evidence from the United States. Journal of Happiness Studies. 2012; 13(1):63-78.

Gerber, Alan S.; Green, Donald P.; Larimer, Christopher W. Social pressure and voter turnout: Evidence from a large-scale field experiment. American Political Science Review. 2008; 102(01): 33-48.

Glied, Sherry; Pine, Daniel S. Consequences and correlates of adolescent depression. Archives of pediatrics \& adolescent medicine. 2002; 156(10):1009-1014. [PubMed: 12361447]

Goldman, Howard H. Mental health: A report of the Surgeon General. 2000 Ohio Department of Mental Health.

González, Hector M.; Vega, William A.; Williams, David R.; Tarraf, Wassim; West, Brady T.; Neighbors, Harold W. Depression care in the United States: too little for too few. Archives of General Psychiatry. 2010; 67(1):37-46. [PubMed: 20048221]

Hill, Kim Quaile; Leighley, Jan E. The policy consequences of class bias in state electorates. American Journal of Political Science. 1992:351-365.

Hillygus, DSunshine. The missing link: Exploring the relationship between higher education and political engagement. Political Behavior. 2005; 27(1):25-47.

Hirschfeld, Robert MA.; Keller, Martin B.; Panico, Susan; Arons, Bernard S.; Barlow, David; Davidoff, Frank; Endicott, Jean; Froom, Jack; Goldstein, Michael; Gorman, Jack M., et al. The National Depressive and Manic-Depressive Association consensus statement on the undertreatment of depression. Jama. 1997; 277(4):333-340. [PubMed: 9002497]

Huckfeldt, Robert; Sprague, John. Political Parties and Electoral Mobilization: Political Structure, Social Structure, and the Party Canvass. American Political Science Review. 1992; 86(01):70-86.

Humensky, Jennifer; Kuwabara, Sachiko A.; Fogel, Joshua; Wells, Corrie; Goodwin, Brady; Van Voorhees, Benjamin W. Adolescents with depressive symptoms and their challenges with learning in school. The Journal of School Nursing. 2010; 26(5):377-392. [PubMed: 20606058] 
Imai, Kosuke; Keele, Luke; Yamamoto, Teppei, et al. Identification, inference and sensitivity analysis for causal mediation effects. Statistical Science. 2010; 25(1):51-71.

Kessler, Ronald C.; McGonagle, Katherine A.; Zhao, Shanyang; Nelson, Christopher B.; Hughes, Michael; Eshleman, Suzann; Wittchen, Hans-Ulrich; Kendler, Kenneth S. Lifetime and 12-month prevalence of DSM-III-R psychiatric disorders in the United States: results from the National Comorbidity Survey. Archives of general psychiatry. 1994; 51(1):8. [PubMed: 8279933]

Kessler, Ronald C.; Berglund, Patricia; Demler, Olga; Jin, Robert; Koretz, Doreen; Merikangas, Kathleen R.; Rush, AJohn; Walters, Ellen E.; Wang, Philip S. The epidemiology of major depressive disorder: results from the National Comorbidity Survey Replication (NCS-R). Jama. 2003; 289(23):3095-3105. [PubMed: 12813115]

Klick, Jonathan; Markowitz, Sara. Are mental health insurance mandates effective? Evidence from suicides. Health Economics. 2006; 15(1):83-97. [PubMed: 16145720]

Lavretsky, Helen; Kumar, Anand. Clinically significant non-major depression: old concepts, new insights. The American journal of geriatric psychiatry. 2002; 10(3):239-255. [PubMed: 11994211]

Lewinsohn, Peter M.; Rohde, Paul; Seeley, John R.; Klein, Daniel N.; Gotlib, Ian H. Psychosocial functioning of young adults who have experienced and recovered from major depressive disorder during adolescence. Journal of abnormal psychology. 2003; 112(3):353. [PubMed: 12943014]

Mathers, Colin; Fat, Doris Ma; Boerma, JT. The global burden of disease: 2004 update. 2008 World Health Organization.

McClurg, Scott D. Social networks and political participation: The role of social interaction in explaining political participation. Political Research Quarterly. 2003; 56(4):449-464.

Meadows, Sarah O.; Brown, J Scott; Elder, Glen H, Jr. Depressive symptoms, stress, and support: Gendered trajectories from adolescence to young adulthood. Journal of Youth and Adolescence. 2006; 35(1):89-99.

Melges, Frederick T.; Bowlby, John. Types of hopelessness in psychopathological process. Archives of General Psychiatry. 1969; 20(6):690. [PubMed: 4890814]

Muñoz, Rodrigo A.; McBride, Margaret E.; Brnabic, Alan JM.; López, Carlos J.; Hetem, Luiz Alberto B.; Secin, Ricardo; Dueñas, Héctor J. Major depressive disorder in Latin America: the relationship between depression severity, painful somatic symptoms, and quality of life. Journal of affective disorders. 2005; 86(1):93-98. [PubMed: 15820276]

Murphy, Elaine. The impact of depression in old age on close social relationships. The American journal of psychiatry. 1985

Olfson, Mark; Marcus, Steven C.; Druss, Benjamin; Elinson, Lynn; Tanielian, Terri; Pincus, Harold Alan. National trends in the outpatient treatment of depression. Jama. 2002; 287(2):203-209. [PubMed: 11779262]

Oliver, Mike. The individual and social models of disability. Joint workshop of the living options Group and the Research Unit of the Royal College of Physicians. 1990; 23

Organization, World Health. International statistical classification of diseases and related health problems. World Health Organization. 2004; 1

Pacheco, Julie; Fletcher, Jason. Incoporating health into studies of political behavior: Evidence that adolescent and maternal health impact youth voter turnout. 2014 Unpublished.

Pattie, Charles; Johnston, Ron. Voter turnout at the British General Election of 1992: Rational choice, social standing or political efficacy? European Journal of Political Research. 1998; 33(2):263-283.

Plutzer, Eric. Becoming a habitual voter: Inertia, resources, and growth in young adulthood. American political science review. 2002; 96(01):41-56.

Plutzer, Eric; Wiefek, Nancy. Family Transitions, Economic Status, and Voter Turnout Among African-American Inner-City Women*. Social science quarterly. 2006; 87(3):658-678.

Puig-Antich, Joaquim; Kaufman, Joan; Ryan, Neal D.; Williamson, Douglas E.; Dahl, Ronald E.; Lukens, Ellen; Todak, George; Ambrosini, Paul; Rabinovich, Harris; Nelson, Beverly. The psychosocial functioning and family environment of depressed adolescents. Journal of the American Academy of Child \& Adolescent Psychiatry. 1993; 32(2):244-253. [PubMed: 8444751]

Radloff, Lenore Sawyer. The CES-D scale a self-report depression scale for research in the general population. Applied psychological measurement. 1977; 1(3):385-401.

Rosenstone, Steven; Hansen, John M. Mobilization, participation and democracy in America. 1993 
Rubin, Kenneth H.; Coplan, Robert J. Paying attention to and not neglecting social withdrawal and social isolation. Merrill-Palmer Quarterly. 2004; 50(4):506-534.

Schur, Lisa; Adya, Meera. Sidelined or mainstreamed? Political participation and attitudes of people with disabilities in the United States. Social Science Quarterly. 2013; 94(3):811-839.

Schur, Lisa; Shields, Todd; Kruse, Douglas; Schriner, Kay. Enabling democracy: disability and voter turnout. Political Research Quarterly. 2002; 55(1):167-190.

Schur, Lisa; Shields, Todd; Schriner, Kay. Can I make a difference? Efficacy, employment, and disability. Political Psychology. 2003; 24(1):119-149.

Snyder, CRichard. Hope theory: Rainbows in the mind. Psychological Inquiry. 2002; 13(4):249-275.

Stewart, Walter F.; Ricci, Judith A.; Chee, Elsbeth; Hahn, Steven R.; Morganstein, David. Cost of lost productive work time among US workers with depression. Jama. 2003; 289(23):3135-3144. [PubMed: 12813119]

Tingley, Dustin; Yamamoto, Teppei; Hirose, Kentaro; Keele, Luke; Imai, Kosuke. forthcoming. Mediation: R package for causal mediation analysis. Journal of Statistical Software.

Tse, Wai S.; Bond, Alyson J. The Impact of Depression on Social Skills: A Review. Journal of Nervous and Mental Disease. 2004

Vaccarino, Anthony L.; Sills, Terrence L.; Evans, Kenneth R.; Kalali, Amir H. Prevalence and association of somatic symptoms in patients with Major Depressive Disorder. Journal of affective disorders. 2008; 110(3):270-276. [PubMed: 18280580]

Verba, Sidney; Nie, Norman H. Participation in America: Political democracy and social equality. University of Chicago Press; 1972.

\section{Appendix A}

The results of the sensitivity analysis are reported in Table 4 . The values in the "correlation of errors" column indicate how much the error terms from the model predicting the mediator (i.e., social interaction, PID, educational attainment, or personal efficacy) would have to correlate with the error terms from the model predicting the dependent variable (i.e., voting or participation) before the mediating effect would be zero. The column labeled "omitted confounder" indicates how much an omitted confounder would have to correlate with both the mediating variable and the dependent variable before the mediating effect would be zero; the value in this column is the product of those two correlations.

Figure 4 is as an illustrative example of the model one results from Table 4. The left graph shows how the average mediated effect changes as the correlation of the error terms, depicted here as the parameter rho, increases or decreases. The average mediated effect is significantly different from zero when rho equals zero (i.e., uncorrelated errors), but once the value of rho increases to 0.2, (i.e., errors correlated at a value of 0.2 ) the average mediated effect is zero. A perhaps more intuitive way to think about the sensitivity of the results is to ask how much a confounder would have to correlate with both voting or education before the mediated effect became zero. The sensitivity parameter for this value is the product of the correlations of the omitted confounder with voting and with education; in the case of model one, it equals 0.04 . This value is represented as the bold line on the right graph, which indicates when the average mediated effect would be zero. For example, if the confounder has a correlation of 0.2 with voting and 0.2 with education $(0.2 \times 0.2=0.04)$ then the average mediating effect would be zero. 

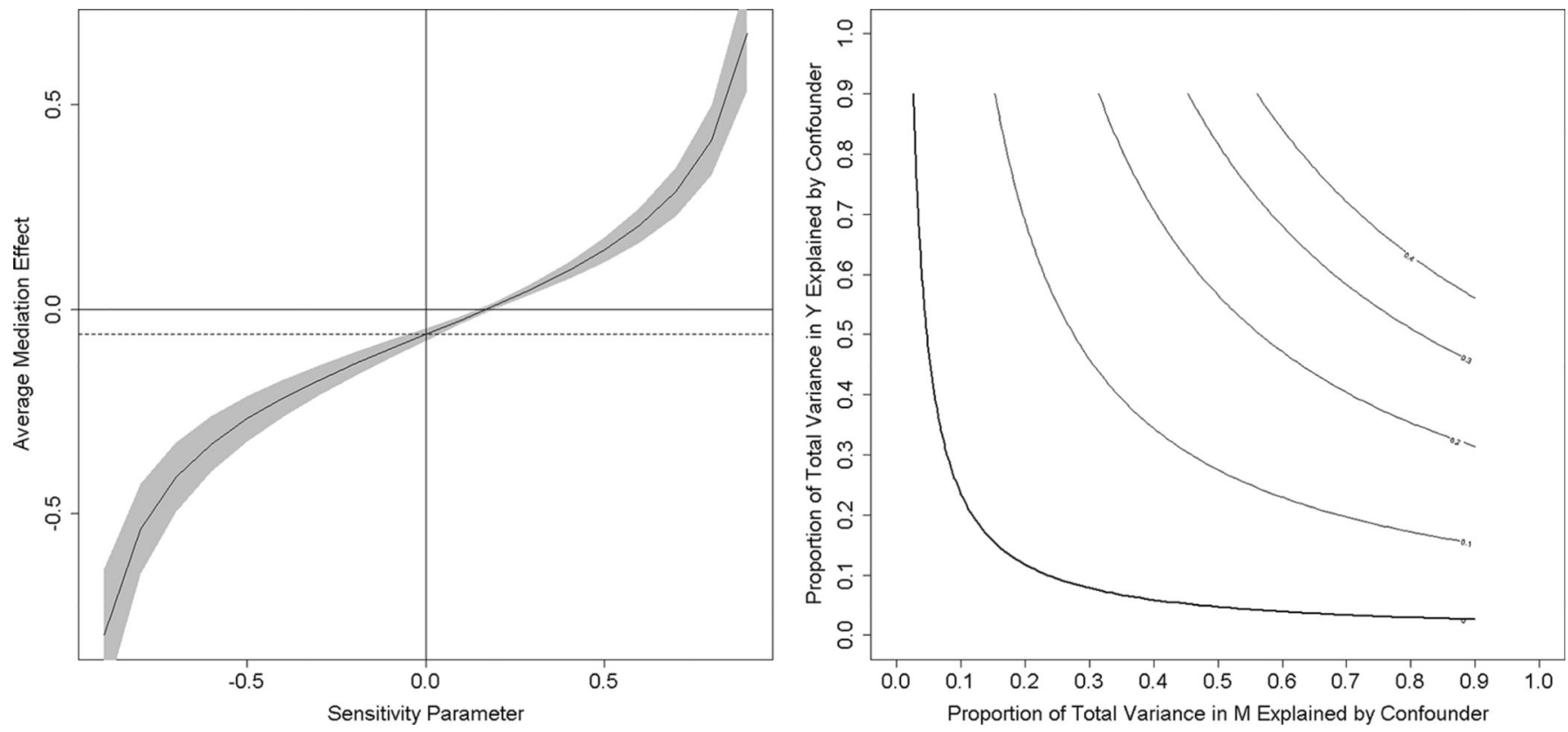

Figure 4.

The sensitivity analyses show that the mediating effect of education is robust.

Table 4

Education and party identification partially explain the effect of adolescent depressed mood.

\begin{tabular}{ccccc}
\hline $\begin{array}{c}\text { Independent } \\
\text { Variable }\end{array}$ & $\begin{array}{c}\text { Mediating } \\
\text { Variable }\end{array}$ & $\begin{array}{c}\text { Dependent } \\
\text { Variable }\end{array}$ & $\begin{array}{c}\text { Correlation } \\
\text { of Errors }\end{array}$ & $\begin{array}{c}\text { Omitted } \\
\text { Confounder }\end{array}$ \\
\hline & $\begin{array}{c}\text { Education } \\
\text { Party Identification } \\
\text { Social Interaction }\end{array}$ & Voting & $-.17^{*}$ & $-.11^{*}$ \\
& $\begin{array}{c}\text { Personal Efficacy } \\
\text { Adolescent } \\
\text { Depressed } \\
\text { Mood }\end{array}$ & & $-.17^{*}$ & $-.13^{*}$ \\
\cline { 2 - 5 } & Education & & $-.18^{*}$ & $-.17^{*}$ \\
& $\begin{array}{c}\text { Party Identification } \\
\text { Social Interaction }\end{array}$ & $\begin{array}{c}\text { Political } \\
\text { Participation }\end{array}$ & $-.17^{*}$ \\
& Personal Efficacy & & $-.07^{*}$ & $-.05^{*}$ \\
& & & $-.07^{*}$ & $-.06^{*}$ \\
& & & $-.07^{*}$ \\
\hline
\end{tabular}

p $<0.05$ (two-tailed)

Note: Analyses conducted using the National Longitudinal Study of Adolescent Health. 


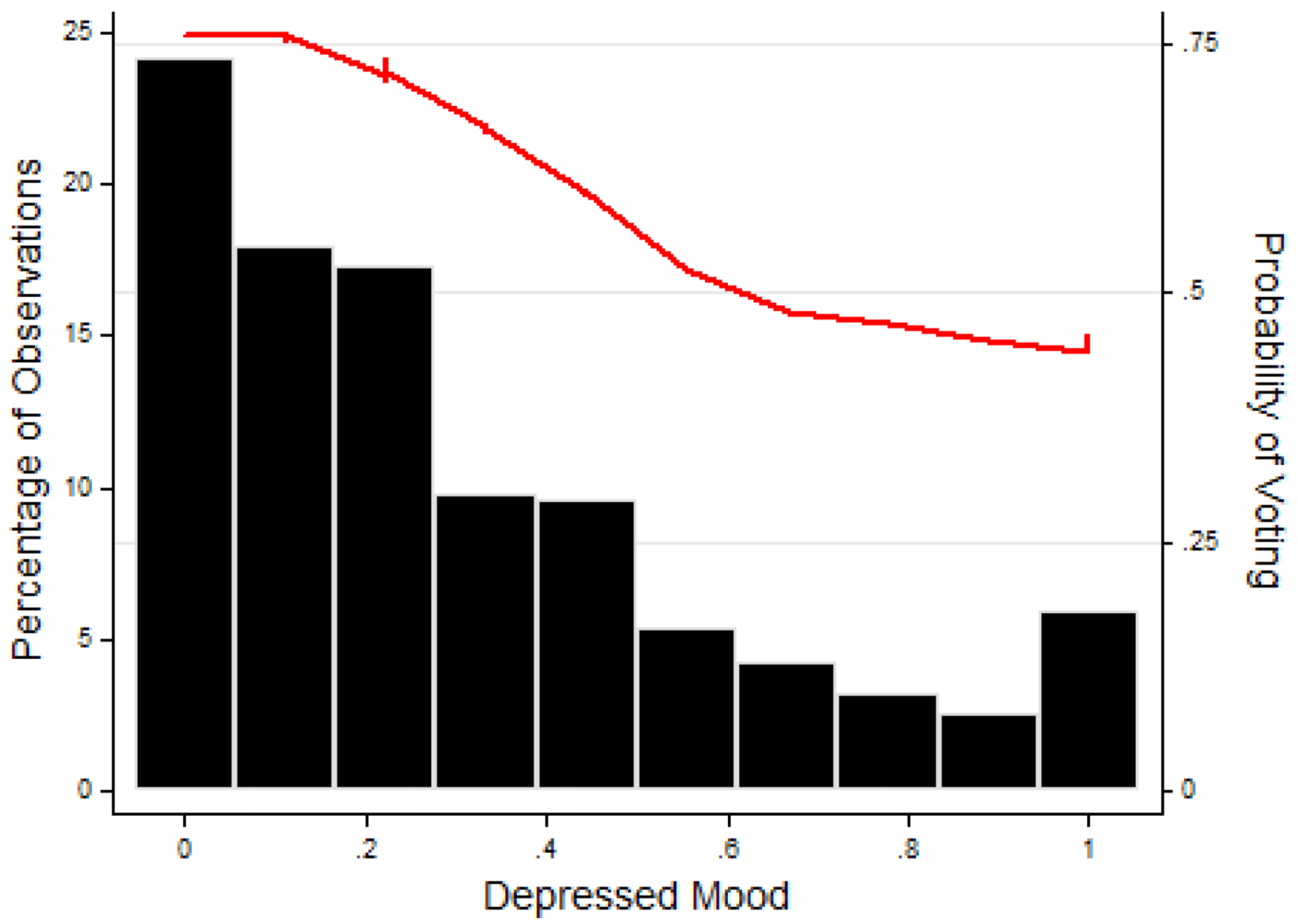

Figure 1.

The probability of voting decreases as the severity of depressed mood increases 


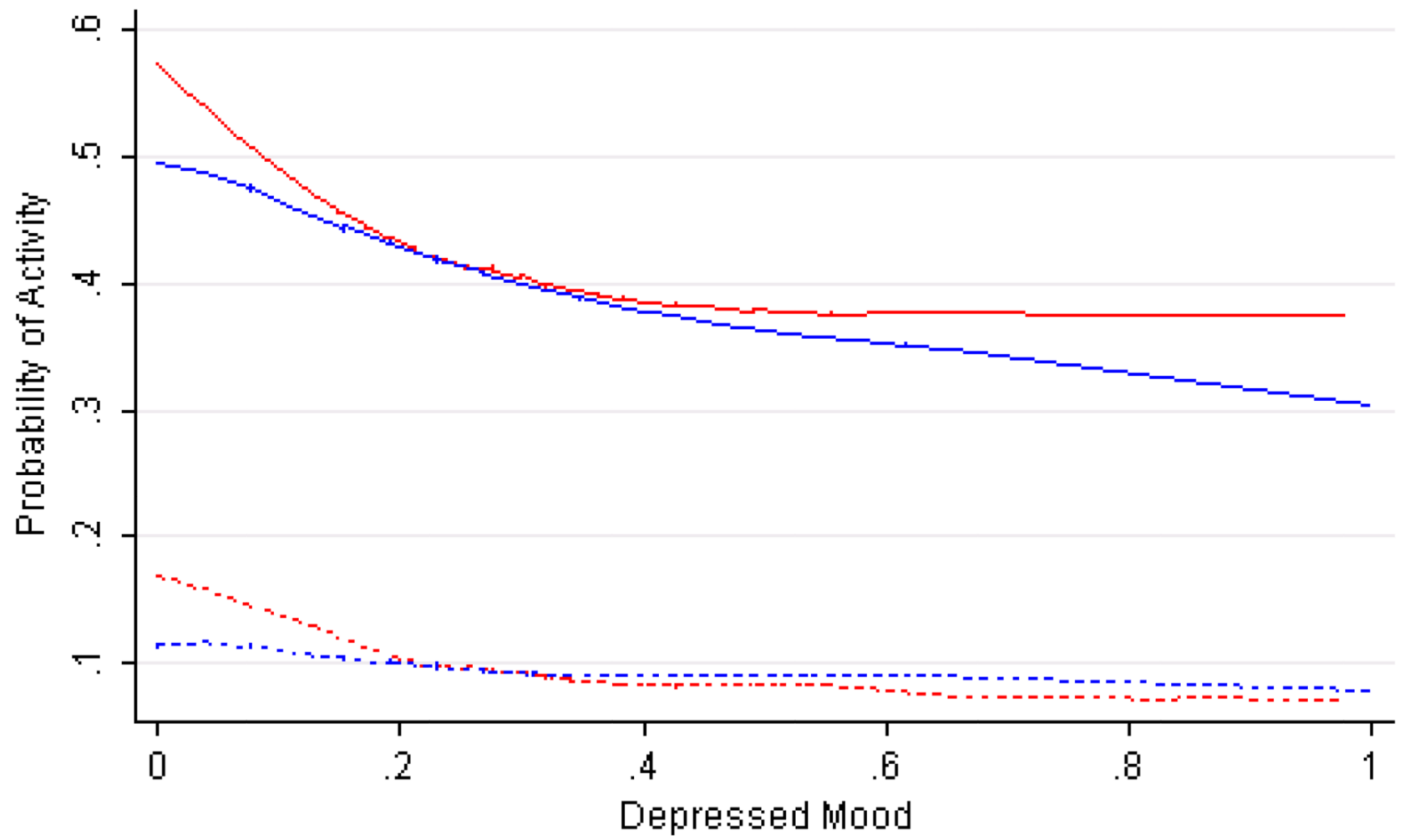

\begin{tabular}{|c|c|}
\hline $\begin{array}{l}\text { - Adolescent DW: Vote } \\
\text { Adult DW: Vote }\end{array}$ & 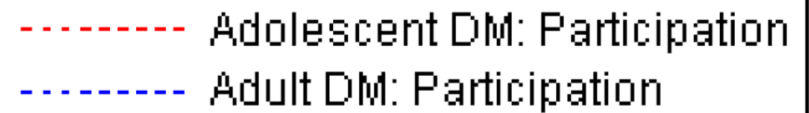 \\
\hline
\end{tabular}

Figure 2.

The probability of political activity decreases as the severity of depressed mood increases 

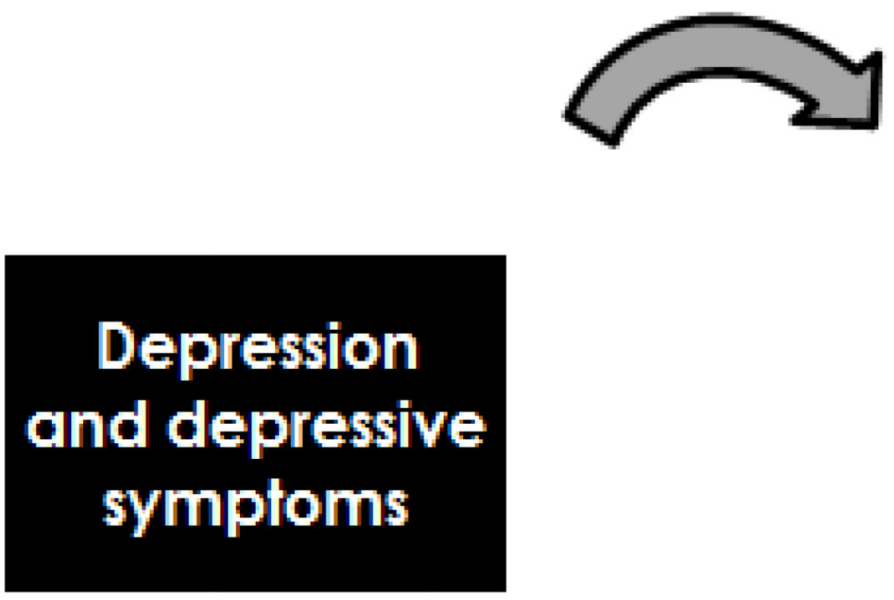

\section{Lower turnout among those with depression}
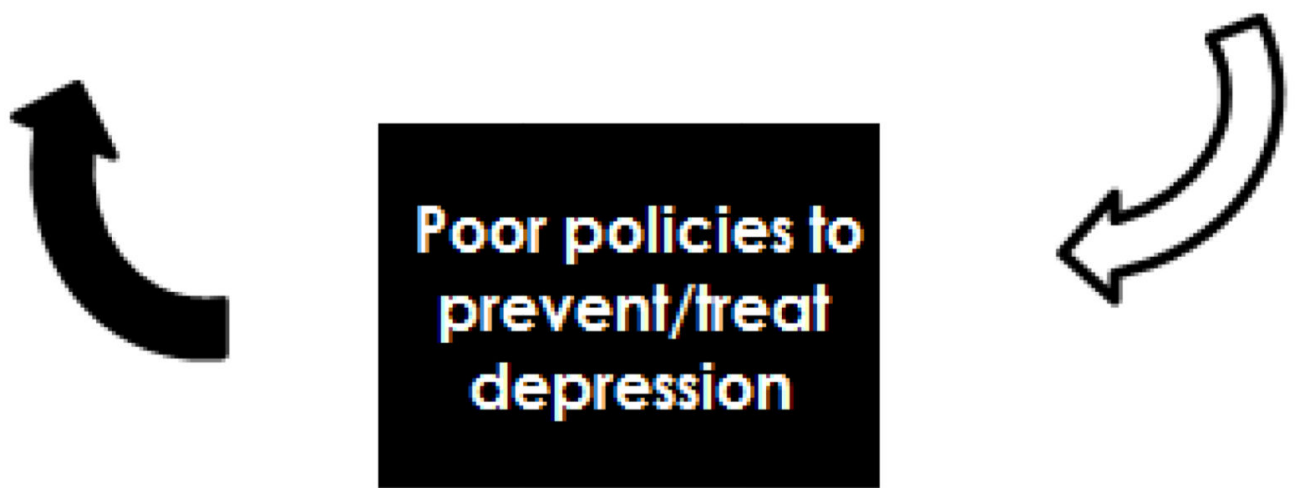

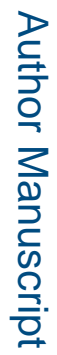

Figure 3.

The political cycle of depression 


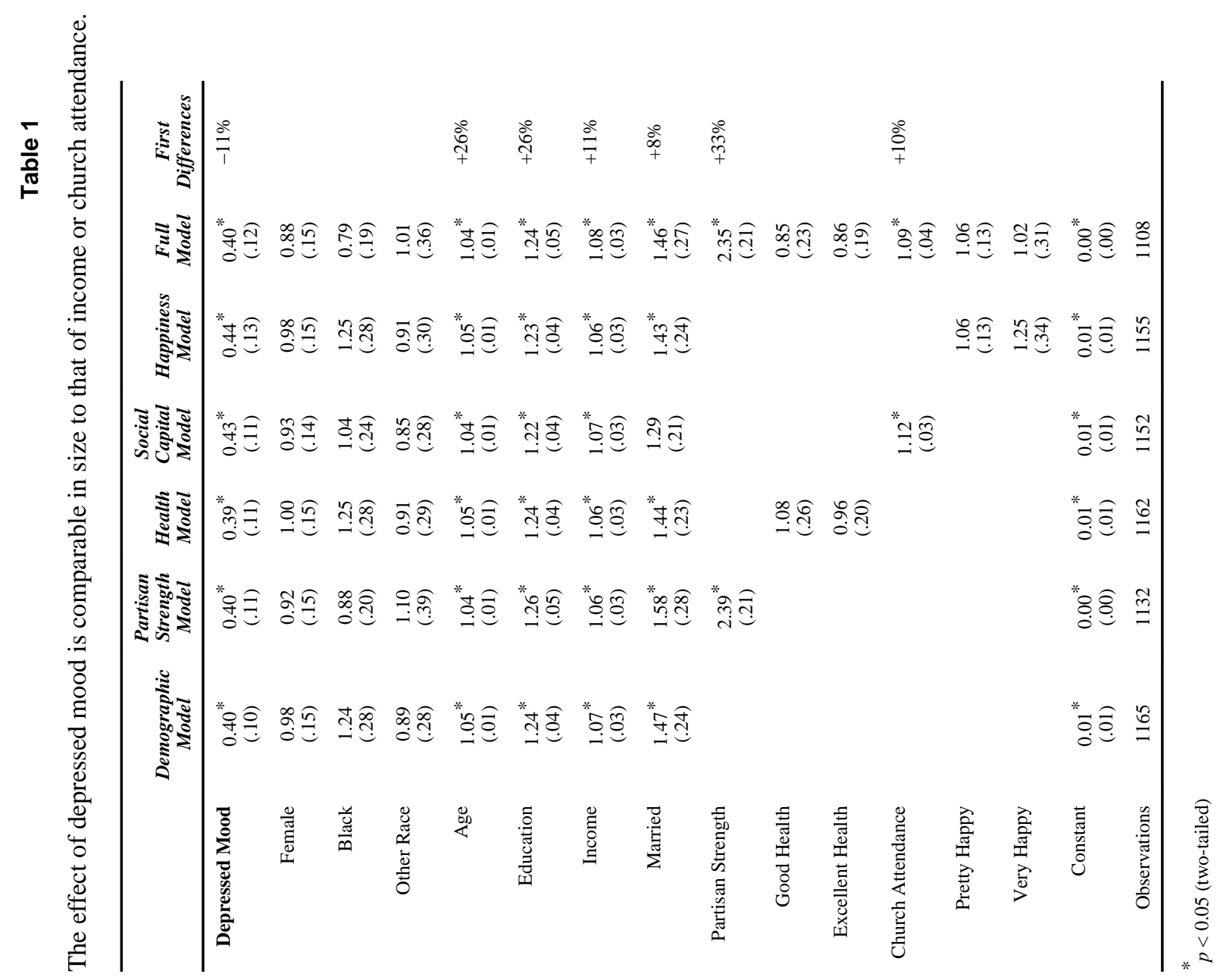




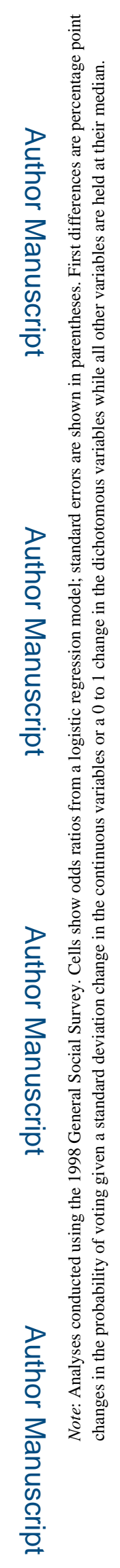


Table 2

Depressed mood in adolescence reduces the probability of voting and participating.

\begin{tabular}{|c|c|c|c|c|}
\hline & Vote & $\begin{array}{c}\text { First } \\
\text { Differences }\end{array}$ & Participation & $\begin{array}{c}\text { First } \\
\text { Differences }\end{array}$ \\
\hline Depressed Mood: Adolescence & $\begin{array}{l}0.60^{*} \\
.14)\end{array}$ & $-4 \%$ & $\begin{array}{c}0.41^{*} \\
.18)\end{array}$ & $-1 \%$ \\
\hline Depressed Mood: Adulthood & $\begin{array}{c}0.63^{*} \\
.14)\end{array}$ & $-3 \%$ & $\begin{array}{l}1.51 \\
(.62)\end{array}$ & \\
\hline Female & $\begin{array}{l}1.02 \\
(.06)\end{array}$ & & $\begin{array}{c}0.67^{*} \\
(.08)\end{array}$ & $-2 \%$ \\
\hline Black & $\begin{array}{l}1.72^{*} \\
.15)\end{array}$ & $+13 \%$ & $\begin{array}{l}0.80 \\
(.12)\end{array}$ & \\
\hline Other Race & $\begin{array}{c}0.68^{*} \\
(.07)\end{array}$ & $-8 \%$ & $\begin{array}{l}1.15 \\
(.22)\end{array}$ & \\
\hline Age & $\begin{array}{l}1.03 \\
(.02)\end{array}$ & & $\begin{array}{l}0.91^{*} \\
. .03)\end{array}$ & $-1 \%$ \\
\hline Education & $\begin{array}{l}1.24^{*} \\
(.03)\end{array}$ & $+19 \%$ & $\begin{array}{l}1.2^{*} \\
(.04)\end{array}$ & $+4 \%$ \\
\hline General Health & $\begin{array}{l}1.47^{*} \\
.22)\end{array}$ & $+4 \%$ & $\begin{array}{l}1.41 \\
(.04)\end{array}$ & \\
\hline Parent Income & $\begin{array}{l}1.02^{*} \\
(.01)\end{array}$ & $+6 \%$ & $\begin{array}{l}1.01 \\
(.01)\end{array}$ & \\
\hline Parent HS & $\begin{array}{l}1.14 \\
(.12)\end{array}$ & & $\begin{array}{l}0.99 \\
(.24)\end{array}$ & \\
\hline Parent College & $\begin{array}{l}1.61^{*} \\
(.18)\end{array}$ & $+12 \%$ & $\begin{array}{c}1.63^{*} \\
(.38)\end{array}$ & $+3 \%$ \\
\hline Parent Civic Engagement & $\begin{array}{l}1.29^{*} \\
.09)\end{array}$ & $+6 \%$ & $\begin{array}{l}1.31^{*} \\
.17)\end{array}$ & $+1 \%$ \\
\hline Constant & $\begin{array}{c}0.01 * \\
(.01)\end{array}$ & & $\begin{array}{c}0.02^{*} \\
(.02)\end{array}$ & \\
\hline Observations & 8,174 & & 8,204 & \\
\hline
\end{tabular}

${ }^{*}<0.05$ (two-tailed)

Note: Analyses conducted using the National Longitudinal Study of Adolescent Health. Cells show odds ratios from a logistic regression model; standard errors are shown in parentheses. First differences are percentage point changes in the probability of voting given a standard deviation change in the continuous variables or a 0 to 1 change in the dichotomous variables while all other variables are held at their median. 

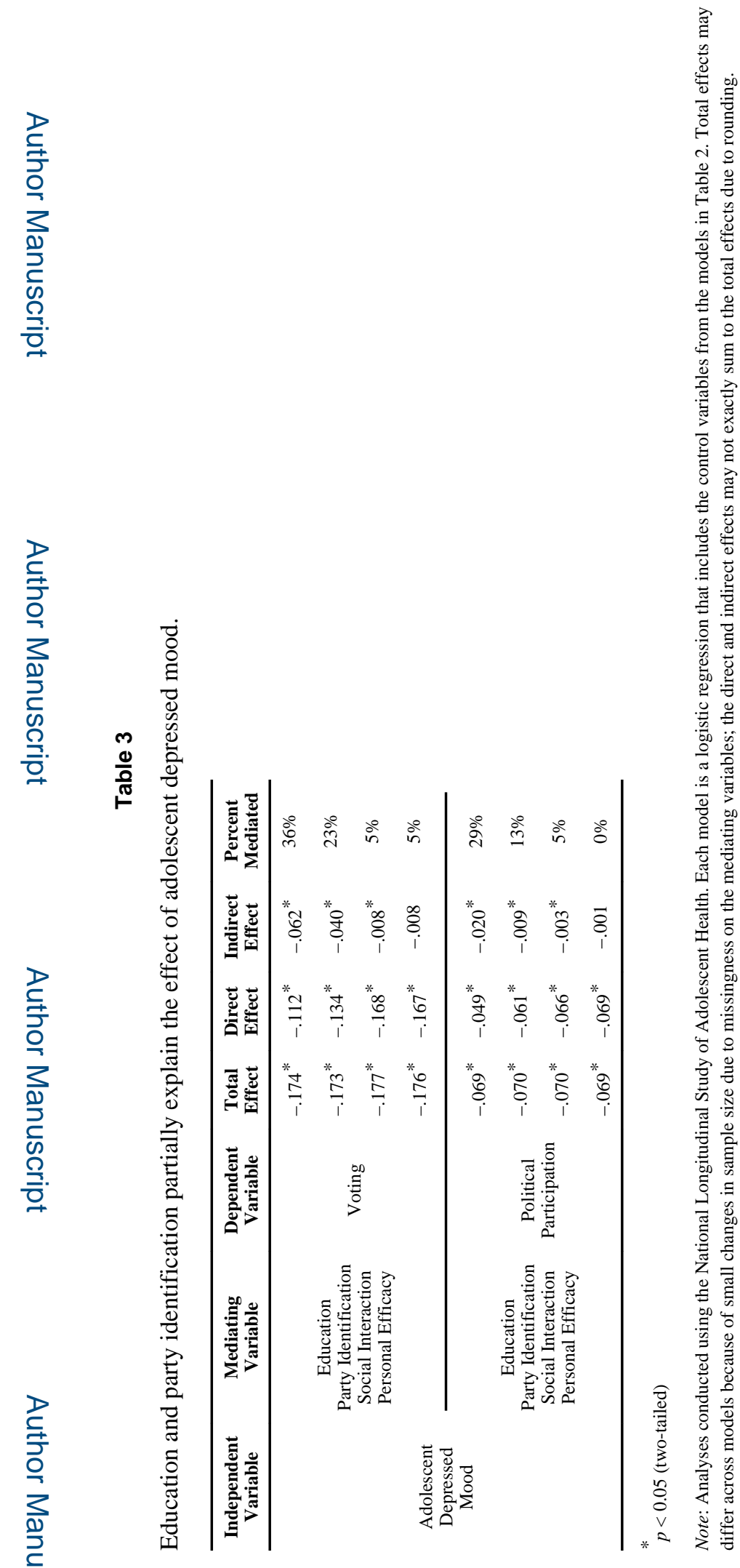